\title{
Landscape genetics of the Alpine newt (Mesotriton alpestris) inferred from a strip-based approach
}

\author{
Guillaume Emaresi · Jérôme Pellet · \\ Sylvain Dubey · Alexandre H. Hirzel • \\ Luca Fumagalli
}

Received: 26 March 2009/ Accepted: 30 August 2009

(C) Springer Science+Business Media B.V. 2009

\begin{abstract}
Habitat destruction and fragmentation are known to strongly affect dispersal by altering the quality of the environment between populations. As a consequence, lower landscape connectivity is expected to enhance extinction risks through a decrease in gene flow and the resulting negative effects of genetic drift, accumulation of deleterious mutations and inbreeding depression. Such phenomena are particularly harmful for amphibian species, characterized by disjunct breeding habitats. The dispersal behaviour of amphibians being poorly understood, it is crucial to develop new tools, allowing us to determine the influence of landscape connectivity on the persistence of populations. In this study, we developed a new landscape genetics approach that aims at identifying land-uses
\end{abstract}

Electronic supplementary material The online version of this article (doi:10.1007/s10592-009-9985-y) contains supplementary material, which is available to authorized users.

G. Emaresi $(\varangle)$ - A. H. Hirzel · L. Fumagalli

Department of Ecology and Evolution, Laboratory

for Conservation Biology, Biophore, University of Lausanne,

1015 Lausanne, Switzerland

e-mail: guillaume.emaresi@unil.ch

J. Pellet

A. Maibach Sàrl, CP 99, Ch. de la Poya 10,

1610 Oron-la-Ville, Switzerland

J. Pellet

Division of Conservation Biology, Institute of Ecology

and Evolution, University of Bern, Erlachstr. 9a,

3012 Bern, Switzerland

\section{S. Dubey}

School of Biological Sciences, University of Sydney,

Heydon-Laurence Bld, A08, Science Road, Sydney,

NSW 2006, Australia affecting genetic differentiation, without a priori assumptions about associated ecological costs. We surveyed genetic variation at seven microsatellite loci for 19 Alpine newt (Mesotriton alpestris) populations in western Switzerland. Using strips of varying widths that define a dispersal corridor between pairs of populations, we were able to identify landuses that act as dispersal barriers (i.e. urban areas) and corridors (i.e. forests). Our results suggest that habitat destruction and landscape fragmentation might in the near future affect common species such as M. alpestris. In addition, by identifying relevant landscape variables influencing population structure without unrealistic assumptions about dispersal, our method offers a simple and flexible tool of investigation as an alternative to least-cost models and other approaches.

Keywords Fragmentation - Landscape genetics · Anthropogenic land-uses · Microsatellites · Amphibians · Dispersal

\section{Introduction}

Fragmentation and destruction of the habitat are among the main threats to biodiversity on a regional and global scale (Opdam et al. 1993; Fahrig 2003), leading to a decrease in suitable habitat areas and to isolation of remaining populations (Hanski and Gilpin 1997). In a metapopulation context (Levins 1969; Hanski and Gilpin 1991), local populations subjected to stochastic extinctions may persist as long as landscape connectivity is sufficient to enable individuals to disperse and recolonise extinct patches (Opdam 1990; Wiens 1997; Hanski 1998, 1999). In addition, connectivity reduces local genetic drift and prevents the accumulation of deleterious mutations in small and 
isolated patches (Keller and Waller 2002). Because landscape and habitat features between patches largely determine dispersal (Wiens et al. 1993; Ricketts 2001; Kindlmann et al. 2005), they can have critical consequences on the population genetic structure (Frankham 1996; Keyghobadi et al. 1999; Arnaud 2003; Bockelmann et al. 2003; Geffen et al. 2004). Because increasing fragmentation tends to reduce the quality of the environment between patches (Fahrig et al. 1995; Carr and Fahrig 2001), landscape connectivity can strongly decline, leading to higher mortality rates within fragmented populations. Accordingly, such phenomenon is of major concern in conservation biology, since endangered species are characterized by small and fragmented populations, and suffer from elevated extinction risks.

In order to reduce the effect of increasing fragmentation, it is crucial to develop new tools of investigation able to determine the influence of landscape connectivity on the persistence of populations. In this context, the emerging discipline of landscape genetics aims to examine the extent to which landscape variables act on the population genetic structure through dispersal (Manel et al. 2003). In particular, it seeks to provide information about interactions between land-uses and evolutionary forces, such as gene flow, genetic drift and selection. It usually proceeds in two steps: (i) detecting genetic discontinuities with suitable molecular approaches and (ii) estimating the correlation of these genetic discontinuities with environmental land-uses, such as dispersal barriers or corridors. Currently, simulation models of varying degree of complexity are increasingly used in landscape genetics (Jepsen et al. 2005). Recent studies contrasted cost-distance models to geneticbased dispersal rates (Stevens et al. 2006), compared hypothetical dispersal routes to a straight-line distance model (Spear et al. 2005), or combined different models (e.g. barriers, isolation by distance, and landscape effects; Cushman et al. 2006). Most of these approaches tested the effects of barriers, such as mountain ridges and elevation (Funk et al. 2005), of agricultural activities (Johansson et al. 2005) or of urbanization pressure (Hitchings and Beebee 1996) on genetic differentiation. However, these approaches suffered from some limitations in statistical significance (e.g. through non-independency of pairwise $F_{\mathrm{ST}}$ estimations). In addition, the lack of knowledge about the dispersal behaviour of certain model species could result in misleading interpretations.

Pond-breeding amphibians can be particularly influenced by the loss and increased isolation of important habitat types (e.g. wetlands) induced by anthropogenic activities (Blaustein et al. 1994), as they are generally characterized by strong annual population fluctuations (Meyer et al. 1998; Trenham et al. 2003), high site fidelity (Smith and Green 2005) and poor ground-dispersal abilities
(Sinsch 1990). Studies conducted on anurans (Vos et al. 2001; Funk et al. 2005; Johansson et al. 2005; Stevens et al. 2006) and urodeles (Spear et al. 2005; Marsh et al. 2005) have shown a strong impact of the landscape on the distribution of the genetic diversity, and particularly a negative effect of anthropogenic land-uses (e.g. roads, railways, urban areas). Nevertheless, through their biphasic life history (aquatic larval phase vs. terrestrial adult phase) and their regular migrations between terrestrial and aquatic habitats, amphibians dispersal behaviour is still poorly understood, due primarily to low probability of capture on land (MacKenzie et al. 2002; Semlitsch 2003). It is worth noting that landscape variables are likely to play a role in every stage of their life cycle, pointing out the necessity to conduct broad analyses into the relative influence of specific landscape variables on amphibian population structure.

To overcome issues of unknown dispersal behaviour, we present a new information-theoretic approach that enables a broad landscape genetics insight without unrealistic assumptions on species dispersal, and identifies the relevant landscape variables. To illustrate such an approach, we have examined the population genetic structure of the alpine newt Mesotriton alpestris, a widespread species in western Switzerland. The species can be considered as a good model because it is an ecological generalist, occupying different habitats ranging from gardens to forested areas (Grossenbacher 1988) and thus could be influenced by a wide array of land-uses. In addition, this species shares many ecological characteristics with some threatened amphibians such as Lissotriton vulgaris or Triturus cristatus. For this reason, information concerning landscape influence on $M$. alpestris genetic structure could be of general interest for other amphibian species, and for the development of conservation and management plans (Semlitsch 2002). This study had two main objectives. The first was to provide insights on the population genetic structure of $M$. alpestris at a regional scale in western Switzerland. According to the occurrence of $M$. alpestris in this area (Grossenbacher 1988), we expected a low genetic differentiation among populations, due to relatively high density. Second, we aimed at testing a novel landscape genetics procedure, using straight-line strips of varying width among each pair of populations. Based on simple and realistic scenarios of cryptic dispersal systems like those found in amphibians, these strips define a dispersal corridor (expected to cover the successful dispersal paths of each individual) between each pair of populations, and in which the land-uses influencing population genetic structure can be detected efficiently. We hypothesized that a standard isolation-by-distance model is not sufficient to explain the observed distribution of allelic frequencies among M. alpestris populations (pairwise $F_{\mathrm{ST}}$ ), and that adding 
some landscape variables significantly improves the prediction power of this standard model.

\section{Materials and methods}

Sampling

Fieldwork was conducted during spring 2005 in western Switzerland. A total of 365 individuals were sampled during the breeding season in 19 ponds within a $672-\mathrm{km}^{2}$ study area (Figure 1, Table 1). The average distance between ponds was $10.6 \mathrm{~km}$, ranging from 0.67 to $26.2 \mathrm{~km}$. In 17 ponds, adults were trapped and morphologically sexed, while larvae were sampled in the additional two ponds (PY (site 18) and MDS (site 19)). Non-destructive samples (Pidancier et al. 2003) were taken from adults, using sterile buccal swabs (Copan), whereas tail clips were taken from larvae. Samples were then stored dry at $-20^{\circ} \mathrm{C}$ before genetic analysis. Buccal swabbing in amphibians has proved to be a very efficient approach, allowing good quality DNA retrieval and very low allelic dropout rates (Broquet et al. 2007).
Microsatellite analysis

Genomic DNA was extracted using a QIAGEN DNeasy ${ }^{\circledR}$ Tissue Kit (QIAGEN), following the manufacturer's instructions. Some additional steps were performed when using buccal swabs: following overnight incubation (lysis step), swabs were centrifuged through a QIA Shredder filter (QIAGEN) and buffer volumes were doubled, except for AW1, AW2 and AE (QIAGEN). DNA was finally eluted twice in a $100 \mu \mathrm{l}$ volume and then stored at $-20^{\circ} \mathrm{C}$. Seven specific microsatellite markers (di- and tetra-nucleotides) were used in this study $\left(T a_{1} C a_{1}, T a_{3} C a_{8}, T a_{4} C a_{4} U\right.$, $\mathrm{Ta}_{1} \mathrm{Caga}_{4}, \mathrm{Ta}_{2} \mathrm{Caga}_{3}, \mathrm{Ta}_{3} \mathrm{Caga}_{1}, \mathrm{Ta}_{3} \mathrm{Caga}_{2}$; Garner et al. 2003). PCRs were performed in a $25 \mu \mathrm{l}$ final volume. Each amplification reaction contained $2 \mu \mathrm{l}$ extraction product, $0.2 \mathrm{mM}$ dNTPs, $0.5 \mu \mathrm{M}$ of both forward and reverse primers, 1× QIAGEN PCR Buffer and 1U QIAGEN Taq polymerase. PCR conditions were the same as in Garner et al. (2003), except for the number of cycles (34-45 cycles) and a final elongation step for $7 \mathrm{~min}$ at $72^{\circ} \mathrm{C}$. PCR products were run on an ABI Prism 3100 automated DNA sequencer (Applied Biosystems). Scoring of alleles for each locus was performed with Genemapper 3.1.2 (Applied Biosystems).
Fig. 1 The study area is located in western Switzerland, on the north shore of Lake Geneva. The map shows forests in light gray and urban areas in dark gray. Sampling locations codes are as in Table 1

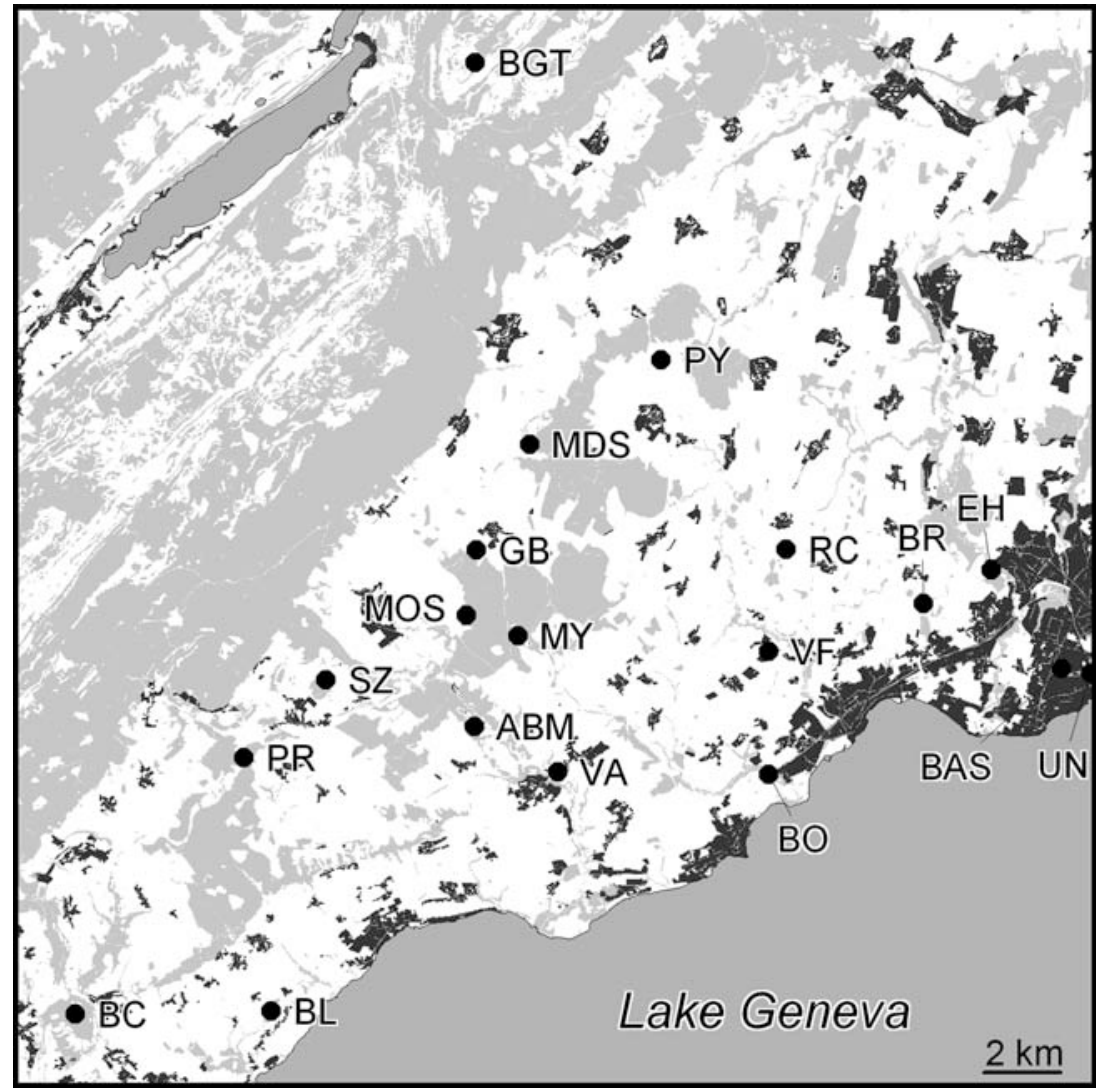


Table 1 Sampling locations, coordinates (Swiss planar coordinate system), number of sampled individuals $\left(N_{\mathrm{s}}\right)$, number of alleles $(k)$, allelic richness (RA), average $F_{\mathrm{IS}}$ values, average pairwise $F_{\mathrm{ST}}$ values, mean expected heterozygosity $\left(H_{\mathrm{s}}\right)$ and mean observed heterozygosity $\left(H_{\mathrm{o}}\right)$ for each of the 19 populations

\begin{tabular}{|c|c|c|c|c|c|c|c|c|c|c|}
\hline \multirow[t]{2}{*}{ Site nr. } & \multirow[t]{2}{*}{ Site name (code) } & \multicolumn{2}{|c|}{ Coordinates } & \multirow[b]{2}{*}{$N_{\mathrm{s}}$} & \multirow[b]{2}{*}{$k$} & \multirow[b]{2}{*}{ RA } & \multirow[b]{2}{*}{$F_{\mathrm{IS}}$} & \multirow[b]{2}{*}{$F_{\mathrm{ST}}$} & \multirow[b]{2}{*}{$H_{\mathrm{s}}$} & \multirow[b]{2}{*}{$H_{\mathrm{o}}$} \\
\hline & & $X$ & $Y$ & & & & & & & \\
\hline 1 & University of Lausanne (UN) & 533895 & 152718 & 25 & 39 & 4.77 & $0.139 \mathrm{NS}$ & 0.052 & 0.638 & 0.549 \\
\hline 2 & Ballens forest (MY) & 519038 & 153688 & 20 & 43 & 5.45 & $0.037 \mathrm{NS}$ & 0.04 & 0.704 & 0.678 \\
\hline 3 & Bois de chêne $(B C)$ & 507539 & 143868 & 20 & 49 & 5.76 & $0.145 \mathrm{NS}$ & 0.031 & 0.673 & 0.575 \\
\hline 4 & $E P F L(B A S)$ & 533130 & 152829 & 20 & 33 & 4.22 & $0.003 \mathrm{NS}$ & 0.103 & 0.531 & 0.530 \\
\hline 5 & Boiron $(B O)$ & 525532 & 150089 & 20 & 39 & 4.85 & $0.095 \mathrm{NS}$ & 0.059 & 0.647 & 0.585 \\
\hline 6 & Echandens $(E H)$ & 531315 & 155400 & 12 & 43 & 5.95 & $-0.007 \mathrm{NS}$ & 0.043 & 0.722 & 0.727 \\
\hline 7 & Arboretum $(A B M)$ & 517899 & 151334 & 20 & 56 & 6.36 & $0.061 \mathrm{NS}$ & 0.026 & 0.677 & 0.635 \\
\hline 8 & Mossières (MOS) & 517689 & 154219 & 19 & 54 & 6.31 & $0.244^{*}$ & 0.03 & 0.706 & 0.534 \\
\hline 9 & Colombier $(R C)$ & 525985 & 155906 & 18 & 53 & 6.14 & $0.271 *$ & 0.044 & 0.707 & 0.515 \\
\hline 10 & Bremblens $(B R)$ & 529543 & 154516 & 20 & 48 & 5.76 & $0.091 \mathrm{NS}$ & 0.06 & 0.703 & 0.639 \\
\hline 11 & Vaudalle (VA) & 520072 & 150149 & 15 & 33 & 4.3 & $-0.04 \mathrm{NS}$ & 0.055 & 0.595 & 0.618 \\
\hline 12 & Gravière de Ballens $(G B)$ & 517959 & 155889 & 20 & 52 & 5.83 & $-0.018 \mathrm{NS}$ & 0.045 & 0.624 & 0.635 \\
\hline 13 & Prévondavaux $(P R)$ & 511921 & 150527 & 20 & 53 & 6.22 & $0.034 \mathrm{NS}$ & 0.025 & 0.694 & 0.670 \\
\hline 14 & Bursinel $(B L)$ & 512622 & 143959 & 20 & 37 & 4.58 & $0.026 \mathrm{NS}$ & 0.08 & 0.642 & 0.626 \\
\hline 15 & Breguettaz (BGT) & 517922 & 168557 & 16 & 52 & 6.41 & $-0.063 \mathrm{NS}$ & 0.028 & 0.676 & 0.718 \\
\hline 16 & Vufflens-le-Château (VF) & 525536 & 153286 & 20 & 46 & 5.57 & $0.047 \mathrm{NS}$ & 0.05 & 0.636 & 0.606 \\
\hline 17 & Saubraz (SZ) & 514049 & 152532 & 22 & 47 & 5.33 & $0.052 \mathrm{NS}$ & 0.038 & 0.642 & 0.609 \\
\hline 18 & Pampigny $(P Y)$ & 522748 & 160831 & 20 & 55 & 6.19 & $0.008 \mathrm{NS}$ & 0.068 & 0.627 & 0.627 \\
\hline 19 & Les Monods (MDS) & 519346 & 158631 & 17 & 59 & 7.18 & $0.034 \mathrm{NS}$ & 0.035 & 0.721 & 0.697 \\
\hline
\end{tabular}

* Significance levels were adjusted for multiple statistical testing with nominal level at 5\%

Genetic structure analyses

All possible pairs of microsatellite loci were tested for genotypic linkage disequilibrium (Goudet et al. 1996), using Fstat 2.9.3. (Goudet 2001). Standard indices of genetic diversity, i.e. total number of alleles, allelic richness (number of alleles corrected for sample size), allelic frequencies, observed and expected heterozygosities $\left(H_{\mathrm{o}}\right.$ and $H_{\mathrm{s}}$; Nei 1987 ), as well as the $F$-statistics ( $F_{\mathrm{IS}}$ and $F_{\mathrm{ST}}$; Weir and Cockerham 1984) were calculated. The significance of $F_{\mathrm{ST}}$ values was estimated over all loci, not assuming random mating within samples (Goudet et al. 1996). Pairwise $F_{\text {ST }}$ values were estimated for all populations. Significance was tested with 2,000 randomisations in Fstat 2.9.3. (Goudet 2001).

Spatial structure was investigated using a Mantel test, by testing whether the regression coefficient between pairwise $F_{\text {ST }}$ and geographic distances was significantly different from zero (Manly 1997). Pattern of isolation by distance was also tested between pairwise $F_{\mathrm{ST}} /\left(1-F_{\mathrm{ST}}\right)$ values and the natural logarithm of geographic distances between all pairs of populations (Rousset 1997).
Landscape structure analysis

Our investigation of the effects of the landscape on genetic differentiation consisted of three main steps: (i) mapping in each cell of a grid overlaid on the study area the occurrence of land-uses that potentially affect dispersal; (ii) measuring the density of each land-use within a rectangular strip between all population pairs and (iii) assessing how much of genetic variance (pairwise $F_{\mathrm{ST}}$ ) can be explained by either distance alone or the relative density of land-uses.

Landscape data originated from the vector format of the 1:25,000 topographical map of Switzerland. The precision of the data is $\sim 10 \mathrm{~m}$ (Swisstopo 2003). We used a subset of the complete coverage aggregated into 14 land-uses (Agriculture, Bush, Forest, Hedgerow, Marsh, Mineral, Orchard, Ponds, Railroad, River, Road1class, Road2class, Urban, and Vine) that could potentially affect newt dispersal. Their occurrence was mapped on 14 10-by-10 m grids using Idrisi 32.2 (Eastman 2002). Spearman's correlation coefficients were calculated in order to verify that only uncorrelated land-uses variables were used for interpretations. 
Between each pair of populations, a rectangular area or strip was delineated symmetrically astride the straight line connecting the centres of the two populations. Such graphical representation delimited a "dispersal corridor" between two populations, which is expected to cover the dispersal routes of each individual that successfully migrated between these two populations. A major advantage of our approach is the possibility to vary the width of the strip, according to the dispersal properties of the model species. Dispersal strategy is highly dependent on the distance at which the species can perceive its environment, also known as perceptual range in dispersal studies. We can easily imagine that short-sighted species (like the alpine newt) have lower perceptual range, resulting in less direct dispersal path, and inversely for large animals (e.g. mammals). Based on the realistic assumption that alpine newts should have a larger width:length ratio than larger species, we tested two classes of width strips (fixed vs. ratio). First, three models of strips were generated with a fixed width of 110,210 and $510 \mathrm{~m}$. Secondly, five others models of strips were produced with different width:length ratio $(1: 1,1: 3$, 1:5, 1:7, 1:9). These latter defined strips of varying widths, depending on the distance between the two populations considered. In order to avoid dependence on strip length, we computed $D_{\mathrm{f}}$ as the frequency of each land-use per strip. This provided for each population pair a set of landscape feature frequencies, which were used as predictors in the subsequent analyses. These analyses were automated with the computer program Frictionnator 1.9.6 (Hirzel and Fontanillas 2007, unpublished; available at: http:// www.unil.ch/biomapper/frictionnator/frictionnator.html).

The first Generalized Linear Model (with Gaussian error distribution and identity link function) was run to estimate percent variation in pairwise $F_{\mathrm{ST}}$ explained by geographic distance $(\delta)$ alone. This null model corresponded to the traditional isolation-by-distance model, commonly used in analyses of genetic population structure (Slatkin 1987). Since our fundamental assumption states that landscape heterogeneities and spatial arrangements of landscape features may strongly affect dispersal success, genetic distance between populations must be better explained by the estimate of a model which considers these factors. Subsequently, this null model was extended with one of the landscape-feature densities $\left(F_{\mathrm{ST}} \sim \delta+D_{\mathrm{f}}\right)$ to test whether the latter independently contributed to the null model predictions. A separate model was built for each landscape variable. We conducted univariate analysis of variance (ANOVA) to test individual response variables.

Owing to the non-independence of pairwise $F_{\mathrm{ST}}$, the significance of these models was unreliable and, consequently, cannot be considered in the results. Previous landscape genetics studies have frequently dealt with this issue by using Partial Mantel (Cushman et al. 2006; Spear et al. 2005), despite its controversy (Raufaste and Rousset 2001; Castellano and Balletto 2002; Rousset 2002). In this study, we adopted the parsimonious framework of Burnham and Anderson's (2002) for model comparison that aimed to rank the candidate models and to select the most plausible model of land-use influence on the genetic structure. This information-theoretic approach is not based on significance, but on the calculated value of Akaike's information criterion (AIC; Akaike 1974) as a measure of model fit (Burnham and Anderson 2002). The lowest AIC value, the closer a candidate model is to the true model. The probability that any given model is actually the best fit out of those tested was measured by its Akaike weight (wAIC; Anderson et al. 2001), the relative-likelihood of the model compared to all others. Whereas the nonindependence of pairwise $F_{\mathrm{ST}}$ have a strong impact on the model significance, the sign of the regression coefficient $\left(\mathrm{S}_{\mathrm{i}}\right)$ and the squared multiple correlation coefficient $\left(\mathrm{R}^{2}\right)$ are considered unbiased, because both indicators are not based on independence assumptions. The indicator $\mathrm{S}_{\mathrm{i}}$ estimated whether the landscape feature limits $(+)$ or favours (-) gene flow, i.e. acted as a dispersal barrier or corridor, respectively, while the indicator $\mathrm{R}^{2}$ provided the proportion of explained variation. All statistical analyses were performed in $\mathrm{R}$ 2.2.1 ( $\mathrm{R}$ development Core Team 2005).

\section{Results}

Genetic structure

A total of 365 adults from 19 ponds were genotyped. Like in Pabijan and Babik (2006), marginally significant linkage disequilibrium was detected between one pair of loci $\left(\mathrm{Ta}_{3} \mathrm{Ca}\right.$ and $\mathrm{Ta}_{4} \mathrm{Ca} \mathrm{a}_{4} \mathrm{U}$ ) after Bonferroni correction $(P<0.001)$. Genetic diversities are provided in Table 1. Overall, 112 alleles were found across the seven microsatellite markers. Allele frequencies are provided in $\mathrm{S}$. Table 1 . The averaged expected heterozygosity per locus $\left(H_{\mathrm{s}}\right)$ was 0.66 whereas the averaged observed heterozygosity $\left(H_{\mathrm{o}}\right)$ was 0.62 . The inbreeding coefficient $F_{\text {IS }}$ was assessed for each population (Table 1). At the population level, two $F_{\text {IS }}$ values were significant (sites 8 and 9; Table 1). Overall $F_{\text {IS }}$ was 0.066 , significantly different from $0(P=0.001)$. Of the seven loci, three of them were significantly in HW disequilibrium $\left(\mathrm{Ta}_{3} \mathrm{Caga}_{1}, \mathrm{Ta}_{1} \mathrm{Caga}_{4}\right.$ and $\mathrm{Ta} \mathrm{Ca}_{1}$ ).

Pairwise $F_{\text {ST }}$ were relatively low, indicating substantial gene flow (S. Table 2). Mean pairwise $F_{\text {ST }}$ values calculated for each population varied from 0.025 to 0.103 (Table 1). The global $F_{\text {ST }}$ value estimated across all loci was low, but significant $(0.049, P=0.001)$. 
Table 2 Comparison between our two classes (class) of strip models (fixed vs. ratio)

\begin{tabular}{llllll}
\hline Class & Width & Mean AIC & SD AIC & Mean R ${ }^{2}(\%)$ & SD R $^{2}(\%)$ \\
\hline Fixed & $110 \mathrm{~m}$ & -688.99 & 11.43 & 7 & 6 \\
& $210 \mathrm{~m}$ & -689.60 & 11.43 & 7 & 6 \\
& $510 \mathrm{~m}$ & -692.28 & 13.57 & 8 & 7 \\
Ratio & $1: 1$ & -690.25 & 13.57 & 7 & 7 \\
& $1: 3$ & -694.78 & 13.47 & 10 & 7 \\
& $1: 5$ & -693.48 & 13.90 & 9 & 7 \\
& $1: 7$ & -692.26 & 13.64 & 8 & 7 \\
& $1: 9$ & -691.26 & 12.94 & 8 & 7
\end{tabular}

A total of eight different models of width strip were analyzed: three models of strips were generated with a fixed width of 110, 210 and $510 \mathrm{~m}$, the five others models were characterized by different width:length ratio (Width). For each variant, the average Akaike Information Criterion among the 15 predictors (Mean AIC) and its standard deviation (SD AIC) were calculated, as well as the average proportion of explained variation (Mean $\mathrm{R}^{2}$ ) and its standard deviation $\left(\mathrm{SD} \mathrm{R} \mathrm{R}^{2}\right)$

Table 3 Results of the 1:3 width:length ratio strip model

\begin{tabular}{lllll}
\hline Variable & $\mathrm{S}_{\mathrm{i}}$ & AIC & wAIC & $\mathrm{R}^{2}(\%)$ \\
\hline Forest & - & -716.26 & 0.495 & 21 \\
Urban & + & -715.28 & 0.303 & 20 \\
Orchard & + & -714.44 & 0.199 & 20 \\
Road1class & + & -706.09 & 0.003 & 16 \\
Railroad & + & -700.19 & 0.000 & 13 \\
Road2class & + & -699.84 & 0.000 & 13 \\
Vineyard & + & -695.77 & 0.000 & 11 \\
Mineral & - & -692.03 & 0.000 & 9 \\
Hedgerow & - & -690.98 & 0.000 & 8 \\
Ponds & - & -686.12 & 0.000 & 5 \\
Agriculture & - & -685.83 & 0.000 & 5 \\
Marsh & - & -680.80 & 0.000 & 2 \\
$\delta$ & & -680.41 & 0.000 & 1 \\
Bush & + & -679.16 & 0.000 & 1 \\
River & + & -678.50 & 0.000 & 1 \\
\hline
\end{tabular}

Each glm was performed between $F_{\mathrm{ST}}$ and one landscape variable (Variable), corrected by the geographical distance $(\delta)$. Sign $\mathrm{S}_{\mathrm{i}}$ of the predictor coefficients, Akaike Information Criterion (AIC), AIC weights (wAIC) and the percentage of explained variation $\left(\mathrm{R}^{2}\right)$ are given for each predictor

Isolation by distance and landscape effect

Regression between pairwise $F_{\mathrm{ST}} /\left(1-F_{\mathrm{ST}}\right)$ values and the natural logarithm of geographic distances was not significant $\left(\mathrm{R}^{2}=0.016, P=0.106\right)$. Moreover, the Mantel test between pairwise $F_{\mathrm{ST}}$ values and geographic distances $(\delta)$ was not significant $(P=0.13)$. The standard isolationby-distance model $\left(F_{\mathrm{ST}} \sim \delta\right)$ showed weak AIC values
$(-680.41)$ and suggested a low relation between both variables $\left(\mathrm{R}^{2}=0.9 \%\right)$, regardless of the strip variant (S. Table 3).

According to the different kind of strips, Spearman's correlation coefficients were on average very low $(0.011 \pm 0.01)$ and did not exceed $80 \%$. Most importantly, no important correlation was detected between the most relevant predictors (e.g. Forest and Urban, mean coefficient: $-0.44 \pm 0.021$ ). When comparing the two classes of strips, the ratio strips revealed generally greater values of AIC and $\mathrm{R}^{2}$ than the fixed-widths strips (Table 2 and $\mathrm{S}$. Table 3). Specifically, the 1:1 width:length ratio strip showed the best AIC score for a single variable (Forest : -722.4) and $\mathrm{R}^{2}$ value (Forest : $23.7 \%$, S. Table 3), whereas the 1:3 width:length ratio strip showed the highest averaged values (AIC $=-694.78, \mathrm{R}^{2}=10 \%$, Table 2). Among the 14 landscape-based models, three of them were consistently identified by the different widths strips methods as most important (Forest, Urban and to a lesser extent Orchard), accounting for more than 99\% of the accumulated Akaike weight (see for example Table 3). Added as explanatory variables, these landscape variables could individually explain up to $23.7,20.5$ and $20.3 \%$ of the $F_{\text {ST }}$ variation, respectively (S. Table 3 ). All other models, including the most parsimonious one that included distance alone $(\delta)$, performed much worse (AIC and $\mathrm{R}^{2}$ in Table 3 and S. Table 3). Interestingly, the sign of the regression between the landscape variables and the pairwise $F_{\mathrm{ST}}$ was consistent among the different models of our method (Table 3 and S. Table 3). More importantly, the results confirmed the expected impacts of the land-uses. For instance, Orchard and Urban displayed positive relationships with population differentiation, whereas Forest showed a negative correlation with pairwise $F_{\mathrm{ST}}$.

\section{Discussion}

\section{Genetic structure}

In panmictic populations, neutral genetic markers (e.g. microsatellites) are expected to show neither an excess nor a deficit of heterozygotes (Hardy-Weinberg equilibrium). However, in the present study three markers $\left(\mathrm{Ta}_{3} \mathrm{Caga}_{1}\right.$, $\mathrm{Ta}_{1} \mathrm{Caga}_{4}$, and $\left.\mathrm{Ta}_{1} \mathrm{Ca} a_{1}\right)$ showed significant departures from Hardy-Weinberg expectations (overall $F_{\mathrm{IS}}=0.066$, $P=0.001)$. The observed deficit in heterozygotes might be due to several reasons including the presence of allelic dropouts, founder effects, substructure within populations (Wahlund effect), inbreeding, or null alleles (polymorphism in the priming sites of the microsatellite locus). A recent study including samples of $M$. alpestris (Broquet et al. 2007), performed with the same microsatellite 
markers employed in our study, showed that buccal swapping is a very efficient approach allowing reliable genotyping with negligible allelic dropouts rates. The presence of substructure was investigated in the present study (by Bayesian clustering analysis; Pritchard et al. 2000), but could not be detected (results not shown). Furthermore, influence of founder effect, substructure, and inbreeding should be similar across all loci in terms of heterozygote deficit, which is not the case (data not shown). The presence of null alleles can be responsible for the deficit in heterozygotes found in our dataset, because such phenomenon is likely to be encountered in populations with a large effective size (Chapuis and Estoup 2007). This hypothesis was confirmed by analysis with Microchecker 2.2.3 (Van Oosterhout et al. 2004; results not shown), corroborating with previous studies (Pabijan and Babik 2006). The impact of microsatellite null alleles on the estimates of population differentiation has been investigated using simulations by Chapuis and Estoup (2007). These authors concluded that $F_{\mathrm{ST}}$ estimates in the presence of null alleles were unbiased in the absence of population substructure and overestimated in cases of significant population differentiation. Given the low global $F_{\mathrm{ST}}$ value across populations $(0.049, P=0.001)$, we consider that, although suffering from some limitations, the information provided by the whole set of loci remains relevant and allows more powerful investigation of the effects of landuses on genetic differentiation.

In contrast to studies in other amphibian species (Funk et al. 2005; Johansson et al. 2005), we found that Alpine newt populations across western Switzerland were characterised by high genetic variation, but low genetic differentiation (overall $F_{\mathrm{ST}}=0.049$ ), and no significant isolation by distance. Mesotriton alpestris inhabiting the entire landscape, the high density of this species in the study area can explain to some extent such outcomes. Interestingly, populations dwelling in urbanized area did not exhibit higher $F_{\mathrm{ST}}$ values than the forest belt ones (Table 1), but showed generally significant differentiations (S. Table 2), suggesting extensive gene flow over the forest area and, conversely, a barrier effect of urban area. Generally, our conclusions corroborated with the study of Pabijan and Babik (2006), conducted across a much larger area (up to $160 \mathrm{~km}$ between sampling sites). Similarly, these authors found low population differentiation, using the same subset of microsatellite markers. Altogether, these data are congruent with studies suggesting either high dispersal ability (Jehle and Sinsch 2007), or high connectivity in a metapopulation structure (Gill 1978). In addition, these results are concordant with the recent suggestion that the dispersal of amphibians among contiguous populations is not as limited as formerly considered (Smith and Green 2005).
Evaluation of the strip-based approach

The choice of an appropriate and realistic model for assessing effects of landscape on genetic diversity needs ideally to involve species characteristics and thus factors affecting their movement. One major dilemma of most landscape studies on amphibian species is the lack of knowledge about the dispersal behaviour of the studied organism (e.g. cryptic species), forcing modellers either to over-simplistic scenarios (i.e. straight-line 'isolation-bydistance' models) or to more complex models based on a priori assumptions (i.e. least-cost models or steppingstone models). In an attempt to overcome these limitations, we developed a straightforward and flexible procedure based on strips between populations (Vos et al. 2001; Arens et al. 2007). As the optimal width:length ratio of the strips depends on the species dispersal strategy and the distance at which it perceives its environment, our landscape genetics methodology presents the major advantage to allow for width variation of the strip. By doing so, our alternative approach enables ecologists to identify the landuse(s) mainly affecting dispersal in a landscape modified by anthropogenic activities and without any a priori assumptions.

Overall, the various variants of our method showed little discrepancy in the results, indicating the presence of a strong signal, which our approach was able to extract. Nevertheless, regarding to the AIC and $\mathrm{R}^{2}$ values, there was a tendency for ratio strips to provide a higher explanation power than constant width strip models (Table 2). In particular, the 1:1 ratio strip appeared to be the most parsimonious strip shape, showing the best AIC and $\mathrm{R}^{2}$ values (S. Table 3). Based on averaged AIC and $\mathrm{R}^{2}$, the 1:3 ratio strip variant showed, however, better overall scores (Table 2), as well as good Akaike weights for three distinct variables (Table 3). The strong performance of these large variants supported our assumption that alpine newts need wider "dispersal corridors" than larger species. Indeed, amphibians are unlikely to travel along a straight line and one predicts that the farther the destination is, the farther from the direct path the individuals will wander. Based on the presence of pineal gland that attracts amphibians to wet habitats, their dispersal strategies could then involve large detours from a simple straight-line path. According to these biological reasons, we advocated that large strip variants should be preferred in our specific case.

Picking up the best model is a critical and delicate process and statistically more robust methods are strongly required in a near future. However, we considered that land-uses comparisons were only possible within a given strip variant, because the selection of the best strip variant for each landscape variable could lead to hardly interpretable results. Although less parsimonious than the 1:1 
ratio strip variant, we argued that the 1:3 ratio strip model displayed overall a better shape (e.g. less overlapping). Therefore, we decided to focus on this particular variant (Table 3) in the following section.

Landscape variables as correlates to gene flow

Although $F_{\mathrm{ST}}$ is unreliable as exact estimate of gene flow or dispersal (Bossart and Prowell 1998), it is effective for estimating genetic differentiation (Whitlock and McCauley 1999) and therefore our results are best described as the effect of landscape on this differentiation. However, our land-uses are expected to impact amphibian genetic structure by favouring or restricting newts dispersal, which in turn would affect genetic differentiation $\left(F_{\mathrm{ST}}\right)$ through the process of gene flow. Then, our results could be interpreted as the effect of landscape on dispersal (Spear et al. 2005).

As compared to the null model of straight-line distance, all alternative models that integrated landscape variables explained a higher proportion of variation of $F_{\mathrm{ST}}$. Forest, Orchard and Urban were clearly identified as land-uses providing a significantly better explanation of pairwise $F_{\text {ST }}$ in almost all models (S. Table 3). It should be noted that prevalence did not seem to affect the inclusion of landscape features in the genetic model. Indeed, among the four most explanatory variables, Forest is one of the more common land-use, while Orchard is much less prevalent in the study area. Incidentally, it seems that it is rather the spatial distribution of these land-uses than their prevalence that affects the genetic differentiation in the models.

As expected, two anthropogenic land-uses, Orchard and Urban areas, showed a significant positive relationship with pairwise $F_{\mathrm{ST}}\left(\mathrm{S}_{\mathrm{i}}\right.$ in Table 3, see also $\mathrm{S}$. Table 3). Although their respective effects were not reliably quantifiable, the percentage of pairwise $F_{\mathrm{ST}}$ variation explained by these land-uses models suggested that both variables could be a hindrance to dispersal. Despite their lower Akaike weight, four others anthropogenic stressors (Railroad, Road1class, Road2class and Vine) interestingly showed the same negative response (Table 3 and S. Table 3). Hence, our results are concordant with recent landscape genetics studies on Rana arvalis (Vos et al. 2001) or R. temporaria (Hitchings and Beebee 1996; Johansson et al. 2005), and reinforce the assumption that habitat fragmentation caused by recent anthropogenic modifications of the landscape can have harmful effects on wild amphibian populations in intensively urbanized regions (Pellet et al. 2004). The relatively high density of settlements in our study area makes it possible to study the effects of anthropogenic activities on M. alpestris populations. The mechanisms hindering gene flow can unfortunately only be guessed, our analysis being strictly correlational. Roadkill, road pollution, winter salting, unsuitability of road surfaces, agrochemicals (pesticides or fertilizers), and other factors probably act in conjunction and are likely decreasing the quality of amphibian habitats.

Conversely, models implemented with the variable Forest confirm our hypothesis of negative relationship with pairwise $F_{\mathrm{ST}}$ (Table 3 and S. Table 3). As suggested above, this relation gives more evidence that forests are good predictor variables of gene flow and are favourable surfaces for the dispersal of newts, with reduced amounts of barriers or disturbances. According to Perret et al. (2003), colonization is not necessarily restricted to juveniles, but adult dispersal represents a strong component of dispersal among populations. Adults overwinter in forests and are, as such, more prone to start and spend a migration journey in such habitats, underlying the importance of forest habitat for M. alpestris. Although this result is intuitive to the majority of amphibian studies, it cannot be excluded that the increase in timber production (following the recent raise in wood prices) might diminish the attractiveness of over-exploited forest areas (Waldick et al. 1999). It is also worth noting that elevation difference did not appeared to drastically increase population differentiation, as suggested in other studies (Funk et al. 2005; Spear et al. 2005). Indeed, the elevated population BGT (alt: $1,080 \mathrm{~m}$ ) showed similar differentiation values than lower population. One interpretation of this observation is that the Jura mountain ridge in-between can facilitate migration via some landscape elements. This ridge being mainly composed of forest areas, this result points out the importance of an accurate management of such element in western Switzerland, in order to maintain sufficient gene flow between amphibian populations inhabiting both valleys and mountain ridges.

Low population differentiation and weak isolation by distance characterise Alpine newt populations in western Switzerland. Despite the high populations density and the good dispersal ability of $M$. alpestris, favouring substantial gene flow, our landscape-based analysis suggested that the alpine newt could be affected by habitat destruction and landscape fragmentation. The approach described in this study showed unambiguously that distance alone was far from sufficient in explaining genetic differentiation at the regional scale of the studied area. Our knowledge of the system has been greatly enhanced with the addition of other factors. Indeed, three predominant land-uses (urban areas, orchards and forest) explained a relatively high proportion of population differentiation and presumably act as dispersal barriers and corridors, respectively. Our analysis raises important questions relative to landscape element management and species conservation. This study provides some evidence that even widespread and highly tolerant species, such as M. alpestris, are at risk to suffer from anthropogenic activities and landscape management 
in the next future. Our results are in line with the view that habitat fragmentation caused by land conversion to anthropogenic use has a negative impact on gene flow between local populations. Thus, the ever-increasing landscape modification through anthropogenic activities will likely affect all amphibian species, whereas the most threatened ones might get extinct. As a result, incorporating landscape variables in studies of population genetic structure and developing statistical analyses that are able to rigorously quantify the impact of the landscape variables are of major conservation priority in the near future. Finally, it is worth noting that the landscape genetics methodology developed herein can be useful in some particular cases (especially with cryptic species), as an alternative approach to other methodologies (e.g. least-cost models).

Acknowledgments We are grateful to T. Broquet, P. Fontanillas, J. Goudet, N. Perrin and two anonymous reviewers for their comments on earlier versions of this manuscript. We also thank the Conservation de la faune et de la nature in St-Sulpice (Switzerland) for capture authorisation.

\section{References}

Akaike H (1974) New look at statistical-model identification. IEEE Trans Automat Contr AC19:716-723

Anderson DR, Burnham KP, White GC (2001) Kullback-Leibler information in resolving natural resource conflicts when definitive data exist. Wildl Soc Bull 29:1260-1270

Arens P, van der Sluis T, van't Westende WPC, Vosman B, Vos CC, Smulders MJM (2007) Genetic population differentiation and connectivity among fragmented Moor frog (Rana arvalis) populations in The Netherlands. Landscape Ecol 22:1489-1500

Arnaud JF (2003) Metapopulation genetic structure and migration pathways in the land snail Helix aspersa: influence of landscape heterogeneity. Landscape Ecol 18:333-346

Blaustein AR, Wake DB, Sousa WP (1994) Amphibian declinesjudging stability, persistence, and susceptibility of populations to local and global extinctions. Conserv Biol 8:60-71

Bockelmann AC, Reusch TBH, Bijlsma R, Bakker JP (2003) Habitat differentiation vs. isolation-by-distance: the genetic population structure of Elymus athericus in European salt marshes. Mol Ecol 12:505-515

Bossart JL, Prowell DP (1998) Genetic estimates of population structure and gene flow: limitations, lessons and new directions. Trends Ecol Evol 13:202-206

Broquet T, Berset-Braendli L, Emaresi G, Fumagalli L (2007) Buccal swabs allow efficient and reliable microsatellite genotyping in amphibians. Conserv Genet 8:509-511

Burnham KP, Anderson DR (2002) Model selection and inference-a practical information-theoretic approach. Springer, New York

Carr LW, Fahrig L (2001) Effect of road traffic on two amphibian species of differing vagility. Conserv Biol 15:1071-1078

Castellano S, Balletto E (2002) Is the partial mantel test inadequate? Evolution 56:1871-1873

Chapuis MP, Estoup A (2007) Microsatellite null alleles and estimation of population differentiation. Mol Biol Evol 24:621-631
Cushman SA, McKelvey KS, Hayden J, Schwartz MK (2006) Gene flow in complex landscapes: testing multiple hypotheses with causal modeling. Am Nat 168:486-499

Eastman JR (2002) Idrisi 32.2. Clark University, Worcester. http:// www.clarklabs.org

Fahrig L (2003) Effects of habitat fragmentation on biodiversity. Ann Rev Ecol Evol Syst 34:487-515

Fahrig L, Pedlar JH, Pope SE, Taylor PD, Wegner JF (1995) Effect of road traffic on amphibian density. Biol Conserv 73:177-182

Frankham R (1996) Relationship of genetic variation to population size in wildlife. Conserv Biol 10:1500-1508

Funk WC, Blouin MS, Corn PS, Maxell BA, Pilliod DS, Amish S, Allendorf FW (2005) Population structure of Columbia spotted frogs (Rana luteiventris) is strongly affected by the landscape. Mol Ecol 14:483-496

Garner TWJ, Schmidt BR, Hoeck P, Van Buskirk J (2003) Di- and tetranucleotide microsatellite markers for the Alpine newt (Triturus alpestris): characterization and cross-priming in five congeners. Mol Ecol Notes 3:186-188

Geffen E, Anderson MJ, Wayne RK (2004) Climate and habitat barriers to dispersal in the highly mobile grey wolf. Mol Ecol 13:2481-2490

Gill D (1978) The metapopulation ecology of the red-spotted newt, Notophthalmus viridescens (Rafinesque). Ecol Monogr 48:145166

Goudet J (2001) Fstat (version 2.9.3): a program to estimate and test gene diversities and fixation indices. University of Lausanne. Available at: http://www2.unil.ch/popgen/softwares/fstat.htm

Goudet J, Raymond M, deMeeus T, Rousset F (1996) Testing differentiation in diploid populations. Genetics 144:1933-1940

Grossenbacher K (1988) Atlas de distribution des amphibians de Suisse. Ligue Suisse pour la protection de la Nature, Basel

Hanski I (1998) Metapopulation dynamics. Nature 396:41-49

Hanski I (1999) Habitat connectivity, habitat continuity, and metapopulations in dynamic landscapes. Oikos 87:209-219

Hanski I, Gilpin M (1991) Metapopulation dynamics—brief history and conceptual domain. Biol J Linn Soc 42:3-16

Hanski I, Gilpin M (1997) Metapopulation biology: ecology, genetics and evolution. Academic Press, London

Hitchings SP, Beebee TJC (1996) Persistence of British natterjack toad Bufo calamita Laurenti (Anura: Bufonidae) populations despite low genetic diversity. Biol J Linn Soc 57:69-80

Jehle R, Sinsch U (2007) Wanderleistung und Orientierung von Amphibien: eine Übersicht. Zeitschrift für Feldherpetologie 14:137-152

Jepsen JU, Baveco JM, Topping CJ, Verboom J, Vos CC (2005) Evaluating the effect of corridors and landscape heterogeneity on dispersal probability: a comparison of three spatially explicit modelling approaches. Ecol Modell 181:445-459

Johansson M, Primmer CR, Sahlsten J, Merila J (2005) The influence of landscape structure on occurrence, abundance and genetic diversity of the common frog, Rana temporaria. Glob Chang Biol 11:1664-1679

Keller LF, Waller DM (2002) Inbreeding effects in wild populations. Trends Ecol Evol 17:230-241

Keyghobadi N, Roland J, Strobeck C (1999) Influence of landscape on the population genetic structure of the alpine butterfly Parnassius smintheus (Papilionidae). Mol Ecol 8:1481-1495

Kindlmann P, Aviron S, Burel F (2005) When is landscape matrix important for determining animal fluxes between resource patches? In: 6th World Congress of the international-association-for-landscape-ecology (IALE), Darwin, AUSTRALIA, pp $150-158$

Levins R (1969) Some demographic and genetic consequences of environmental heterogeneity for biological control. Bull Entomol Soc Am 15:237-240 
MacKenzie DI, Nichols JD, Lachman GB, Droege S, Royle JA, Langtimm CA (2002) Estimating site occupancy rates when detection probabilities are less than one. Ecology 83:2248-2255

Manel S, Schwartz MK, Luikart G, Taberlet P (2003) Landscape genetics: combining landscape ecology and population genetics. Trends Ecol Evol 18:189-197

Manly BGF (1997) Randomisation and Monte Carlo methods in biology, 2nd edn. Chapman and Hall, London

Marsh DM, Milam GS, Gorham NR, Beckman NG (2005) Forest roads as partial barriers to terrestrial salamander movement. Conserv Biol 19:2004-2008

Meyer AH, Schmidt BR, Grossenbacher K (1998) Analysis of three amphibian populations with quarter-century long time-series. Proc R Soc Lond B Biol Sci 265:523-528

Nei M (1987) Molecular evolutionary genetics. Columbia University Press, New York

Opdam P (1990) Dispersal in fragmented populations: the key to survival. In: Bunce RGH, Howard DC (eds) Species dispersal in agricultural habitats. Belhaven Press, London, pp 3-17

Opdam P, Van Apeldoorn R, Schotmann R, Kalkhoven J (1993) Population responses to landscape fragmentation. In: Vos CC, Opdam P (eds) Landscape ecology of a stressed environment. Chapman and Hall, London, pp 147-171

Pabijan M, Babik W (2006) Genetic structure in northeastern populations of the Alpine newt (Triturus alpestris): evidence for post-Pleistocene differentiation. Mol Ecol 15:2397-2407

Pellet J, Guisan A, Perrin N (2004) A concentric analysis of the impact of urbanization on the threatened European tree frog in an agricultural landscape. Conserv Biol 18:1599-1606

Perret N, Pradel R, Miaud C, Grolet O, Joly P (2003) Transience, dispersal and survival rates in newt patchy populations. J Anim Ecol 72:567-575

Pidancier N, Miquel C, Miaud C (2003) Buccal swabs as a nondestructive tissue sampling method for DNA analysis in amphibians. Herpetol J 13:175-178

Pritchard JK, Stephens M, Donnelly P (2000) Inference of population structure using multilocus genotype data. Genetics 155:945-959. http://pritch.bsd.uchicago.edu/software/structure2_2.html

Raufaste N, Rousset F (2001) Are partial mantel tests adequate? Evolution 55:1703-1705

Ricketts TH (2001) The matrix matters: Effective isolation in fragmented landscapes. Am Nat 158:87-99

Rousset F (1997) Genetic differentiation and estimation of gene flow from F-statistics under isolation by distance. Genetics 145:12191228

Rousset F (2002) Partial mantel tests: reply to Castellano and Balletto. Evolution 56:1874-1875
Semlitsch RD (2002) Critical elements for biologically based recovery plans of aquatic-breeding amphibians. Conserv Biol 16:619-629

Semlitsch RD (2003) Conservation of pond-breeding amphibians. In: Semlitsch RD (ed) Amphibian conservation. Smithsonian Institution, Washington, DC, pp 8-23

Sinsch U (1990) Migration and orientation in anuran amphibians. In: International symposium on homing in animals. Rome, Italy, pp 65-79

Slatkin M (1987) Gene flow and the geographic structure of natural populations. Science 236:787-792

Smith MA, Green DM (2005) Dispersal and the metapopulation paradigm in amphibian ecology and conservation: are all amphibian populations metapopulations? Ecography 28:110-128

Spear SF, Peterson CR, Matocq MD, Storfer A (2005) Landscape genetics of the blotched tiger salamander (Ambystoma tigrinum melanostictum). Mol Ecol 14:2553-2564

Stevens VM, Verkenne C, Vandewoestijne S, Wesselingh RA, Baguette M (2006) Gene flow and functional connectivity in the natterjack toad. Mol Ecol 15:2333-2344

Swisstopo (2003) Vector25. Office Fédéral de la Topographie, Bern

Team RDC (2005) R: a language and environment for statistical computing. R Foundation for Statistical Computing, Vienna

Trenham PC, Koenig WD, Mossman MJ, Stark SL, Jagger LA (2003) Regional dynamics of wetland-breeding frogs and toads: Turnover and synchrony. Ecol Appl 13:1522-1532

Van Oosterhout C, Hutchinson WF, Wills DPM, Shipley P (2004) MICRO-CHECKER: software for identifying and correcting genotyping errors in microsatellite data. Mol Ecol Notes 4:535538. http://www.microchecker.hull.ac.uk/

Vos CC, Antonisse-De Jong AG, Goedhart PW, Smulders MJM (2001) Genetic similarity as a measure for connectivity between fragmented populations of the moor frog (Rana arvalis). Heredity 86:598-608

Waldick RC, Freedman B, Wassersug RJ (1999) The consequences for amphibians of the conversion of natural, mixed-species forests to conifer plantations in southern New Brunswick. Can Field-Nat 113:408-418

Weir BS, Cockerham CC (1984) Estimating $F$-statistics for the analysis of populations structure. Evolution 38:1358-1370

Whitlock MC, McCauley DE (1999) Indirect measures of gene flow and migration: FST not equal 1/(4Nm + 1). Heredity 82:117-125

Wiens JA (1997) Metapopulation dynamics and landscape ecology. In: Hanski I, Gilpin M (eds) Metapopulation biology. Academic Press, San Diego, pp 43-68

Wiens JA, Stenseth NC, Vanhorne B, Ims RA (1993) Ecological mechanisms and landscape ecology. Oikos 66:369-380 